\section{THU0076 ADENOVIRUS MEDIATED GENE TRANSFER OF UROKINASE PLASMINOGEN INHIBITOR INHIBITS ANGIOGENESIS IN EXPERIMENTAL ARTHRITIS}

C Jorgensen, F Apparailly, C Bouquet, V Millet, D Noel, P Yeh, J Sany. ImmunoRheumatology, Lapeyronie, Montpellier, France

\subsection{6/annrheumdis-2001.953}

Background Plasmin is essential for metalloproteases (MMP) activation, endothelial cell migration and degradation of the extracellular matrix. The process is common to neoangiogenesis and pannus formation, and $80 \%$ of synovial cells express urokinase plasminogen activator receptor (UPAR).

Objectives We inhibited plasmin activation by expressing uPA/ uPAR antagonist chimeric molecule (ATF-HSA) through adenoviral mediated gene transfer in experimental arthritis.

Methods Overexpression of ATF-HSA was obtained by IV injection of 109 pfu of a non replicative E1 deleted type 5 adenoviral vector containing murine ATF gene linked to HSA gene under the control of a CMV promoter. Collagen-induced arthritis (CIA) was obtained by immunisation of DBA1 mice with bovine type II collagen in FCA. AdATF-HSA was injected IV on day 25 after immunisation. On day 44, X ray and Immuno-histology of paws were performed. The SCID/hu model was used to assess the effect of adenoviral mediated huATF gene transfer on human rheumatoid synovium angiogenesis.

Results

Conclusion The uPAR antagonist ATF-HSA is a new tool for gene therapy in arthritis. The preventive effect observed may be related to the decrease in angiogenesis rather than inhibition of extracellular matrix degradation.

\section{THU0077 INTERATIONS BETWEEN INFLAMMATORY POLYARTHRITIS AND CARDIOVASCULAR DISEASE}

${ }^{1} \mathrm{PH}$ Dessein, ${ }^{1} \mathrm{AE}$ Stanwix, ${ }^{2} \mathrm{BI}$ Joffe, ${ }^{3} \mathrm{EA}$ Shipton. ${ }^{1}$ Rheumatology; ${ }^{2}$ Carbohydrate and Lipid Metabolism Research Unit; ${ }^{3}$ Pain Relief and Research Unit, CH Baragwanath Hospital, Johannesburg, South Africa

\subsection{6/annrheumdis-2001.954}

Background Inflammatory polyarthritis (IP) and cardiovascular disease (CVD) may share a common predisposition and disease activity in IP may be complicated by worsening of CVD risk factors profiles.

Objectives The aim of the present study was to provide evidence for these hypotheses.

Methods A literature search on predisposing factors for IP and a case controlled study in 87 IP patients (38 rheumatoid arthritis, 29 spondyloarthropathy and 20 undifferentiated inflammatory arthritis) on CVD risk factors were performed.

Results Recently identified predisposing factors for IP bear remarkable similarities to CVD risk factors. They include ageing, obesity, smoking, elevated cholesterol and apolipoprotein (apo) (a) concentrations, subtle hypoadrenalism, decreased unsaturated fat intake and antioxidant concentrations, no alcohol intake, infections and stressful life events. Indeed, activation of nuclear factor kappa B, monoclonal expansion of proinflammatory $\mathrm{CD} 4{ }^{+} \mathrm{CD} 28-\mathrm{T}$ cells and acute phase responses (APR), the mutually reinforcing relationship between obesity/insulin resistance (IR) and hypoadrenalism and, endothelial dysfunction may each play a pivotal role in both IP and CVD. In established IP, disease activity associates with the presence of APR, raised apo (a), cholesterol/HDL-cholesterol and apo B/A1 ratios, IR and decreased dehydroepiandrosterone sulphate (DHEAS) concentrations, thereby worsening CVD risk factor profiles. Three studies reported a $60-80 \%$ excess CVD mortality in rheumatoid arthritis. In a more recent investigation, in which disease modifying agents were instituted soon after disease onset, the 10 year survival was similar to the general population. In our controlled study, IP was associated with a positive family history for coronary artery disease $(\mathrm{p}<0.03)$. Twenty five $(29 \%)$ patients had IR and this could be accounted for by the APR and body mass index (BMI). Cholesterol/HDL-cholesterol ratios were elevated and this was only partially attributable to the APR, BMI and IR. Twenty four (28\%) patients had decreased DHEAS concentrations and in women, this could not be fully explained by the APR, IR, disease duration, previous glucocorticoid and current NSAID usage.

Conclusion Further elucidation of etiopathogenetic mechanisms shared by IP and CVD may yield more effective therapies for both conditions. Meanwhile, CVD risk factor profiles should be addressed in IP management.

\section{REFERENCES}

1 Dessein $\mathrm{PH}$, et al. Rheumatology 2001, in press

2 Liuzzo G, et al. Circulation 2000;102: 2883-8

3 Weyand CM, et al. Arch Immunol Ther Exp (Warsz) 2000;48:429-35

4 Kroot EJ, et al. Ann Rheum Dis. 2000;59:954-8

\section{THU0078 ANTIARTHRITIC EFFECT OF SALBUTAMOL ALONE AND IN COMBINATION WITH PENTOXYPHILINE ON ADJUVANT ARTHRITIS IN RATS}

R Bradunaite, E Bernotiene, L Leonaviciene, D Vaitkiene. Laboratory of Experimental Pathology, Institute of Experimental and Clinical Medicine, Vilnius, Lithuania

\subsection{6/annrheumdis-2001.955}

Background The beta-2 ?adrenergic agonist salbutamol (S) and the phosphodiesterase inhibitor pentoxifylline $(\mathrm{P})$ are reported to be the elevators of cAMP and the suppressors of Th1 response. $^{1,2}$ Elevation of intracellular cAMP reduces the production of IL-12 and TNF, the important cytokines in the pathogenesis of rheumathoid arthritis (RA).

Objectives To evaluate the antiarthritic effect of $S$ alone and in combination with $\mathrm{P}$ on the model of $\mathrm{RA}$ in animals - the expressed adjuvant arthritis (AA) in rats.

Methods Experiment was performed on 30 female Lewis rats with AA induced by a single subplantar injection of $0,1 \mathrm{ml}$ of complete Freud's adjuvant into the left hind paw. On day 8 of experiment, rats were assigned into 3 groups with the similar mean scores of joint swelling and the treatment with $S$ (1st group) and $\mathrm{S}+\mathrm{P}$ (2nd) was started. Control group (3rd) received $1 \mathrm{ml}$ of starch gel. Drugs were prepared as the suspension in $1 \%$ starch gel and administered intragastrically 5 times a week in a volume of $1 \mathrm{ml}$ in following doses: $\mathrm{S}$ ? $8,5 \mathrm{mg} / \mathrm{kg}$ and $\mathrm{P}$ ? 500 $\mathrm{mg} / \mathrm{kg}$. The duration of treatment ? 2 weeks. Body weight and joint swelling were monitored 3 times a week. Haematological and pathomorphological changes were evaluated at the end of experiment (day 23).

Results $S$ significantly $(\mathrm{p}<0,02)$ reduced joint swelling by $38,3 \%$ at the end of experiment. Combined treatment with $\mathrm{S}+\mathrm{P}$ was more effective and significantly $(\mathrm{p}<0,02-0,01)$ diminished joint swelling starting at day 18 (by 36\%) till the end of experiment (by 44\%). Polyarthritis developed in $70 \%$ of animals treated with S, $60 \%$ - with S+P and $90 \%$ - of control group. The marked improvement $(\mathrm{p}<0,02)$ of blood indices was 